\title{
Mesoporous RF-Xerogels by Facile Hydrothermal Synthesis
}

\author{
Sakhon Ratchahat ${ }^{1, a}$, Satoshi Kodama ${ }^{1, \mathrm{~b}}$, Hidetoshi Sekiguchi ${ }^{1, \mathrm{c}}$, \\ Wiwut Tanthapanichakoon ${ }^{1, \mathrm{~d}}$, Khalid Al-Ali, ${ }^{2, \mathrm{e}}$ Tawatchai Charinpanitkul, ${ }^{3, \mathrm{f}}$, \\ Apinan Soottitantawat ${ }^{3, g}$, Apiluck Eiad-Ua ${ }^{3, h}$, and Kajornsak Faungnawakij ${ }^{5, i}$ \\ 1 Dept. of Chem. Eng., Tokyo Institute of Technology, Tokyo 152-8550, Japan \\ 2 Dept. of Chem. \& Env. Eng., Masdar Institute of Science and Technology, Abu Dhabi, UAE \\ 3 CoE in Particle Tech. Fac. of Eng., Chulalongkorn University, Bangkok, 10330, Thailand \\ 4 College of Nanotechnology, KMITL, Bangkok 10520, Thailand \\ 5 National Nanotechnology Center, NSTDA, Patumthani 12120, Thailand
}

E-mail: aratchahat.s.aa@m.titech.ac.jp (Corresponding author), bskodama@chemeng.titech.ac.jp, chsekiguc@chemeng.titech.ac.jp, ${ }^{d}$ wiwutt@chemeng.titech.ac.jp, ekalali@masdar.ac.ae, ${ }^{f}$ ctawat@chula.ac.th, sapinan.s@chula.ac.th, hkeapiluc@kmitl.ac.th, ikajornsak@nanotech.or.th

\begin{abstract}
Mesoporous resorcinol-formaldehyde (RF) xerogels were difficult to obtain by conventional sol-gel polymerization at atmospheric pressure because the resulting tenuous RF-gel structures tended to shrink or collapse during subsequent hot-air drying. To avoid this problem, costly and energy-intensive supercritical drying and freeze-drying are often used. In this work the main goal was to produce high-quality RF xerogels with good mesoporosity and high surface area by employing a hydrothermal process. The hydrogel synthesis was carried out in an autoclave at elevated temperature and pressure in order to sufficiently strengthen its network structure. The initial reactant ratio was held constant to search for most suitable hydrothermal temperature and initial $\mathrm{pH}$. The experimental results showed that the reaction in the autoclave at $140{ }^{\circ} \mathrm{C}$ and initial $\mathrm{pH}$ of 6 could successfully produce RF xerogels with good mesoporosity (peaking pore radius $r_{\text {peak }}=2.38$ $\mathrm{nm}$ ), high specific surface area and large pore volume. The hydrothermal process was on the overall relatively simple, low-cost, and less time-consuming compared to the conventional atmospheric method.
\end{abstract}

Keywords: Mesoporous materials, RF xerogels, hydrothermal process.

ENGINEERING JOURNAL Volume 19 Issue 3

Received 27 May 2015

Accepted 27 May 2015

Published 5 June 2015

Online at http://www.engj.org/

DOI:10.4186/ej.2015.19.3.95 


\section{Introduction}

Resorcinol-formaldehyde (RF) gels have received considerable attention in the literature over past decades due to its useful properties which include high porosities $(>80 \%)$ in micropore to mesopore range, high specific surface areas $\left(400-1200 \mathrm{~m}^{2} / \mathrm{g}\right)$, and large pore volumes $[1,2]$. RF gels also exhibit extremely low thermal conductivity resulting from its porous structure. In addition, RF gels could be carbonized at high temperature under inert atmosphere to produce thermally stable pure-carbon structures called RF carbon gels [3]. Achieving the desired mesoporosity of RF carbon gels has been the focus of a majority of many research works regarding their synthesis since it is often the mesoporosity that determines their industrial applications [4, 5]. Application of mesoporous RF carbon gels includes supporting materials for catalysts [6], electrode materials for electric double layer capacitors (EDLC) [7], column chromatography (HPLC and GC) packing [8], adsorbents [9], thermal insulators [10] and so on. These carbon gels have a clear advantage over microporous materials regarding the adsorption and transformation of large organic molecules. Usable to direct medicines to their target organs (controlled drug delivery and targeting), mesoporous RF carbon gels may also play an important role in the therapeutic field [5].

Although mesoporous RF gels could be prepared via a template method (soft/hard template), a simple, low-cost, template-free method is preferable if it can be achieved by optimizing initial synthesis parameters and regulating the evaporation of water solvent during the drying step [13,14]. Synthesis of RF gels is conventionally conducted in a similar way to phenolic resin preparation, using sol-gel polycondensation. Briefly, reactants including resorcinol (R) and formaldehyde (F) are mixed at an appropriate ratio with water (W) as solvent in the presence of catalyst (C), usually a basic catalyst such as sodium carbonate [11]. Then the clear solution is heated to a specific temperature $\left(<100^{\circ} \mathrm{C}\right)$ at nearly atmospheric pressure and held for a period of time to form stable, cross-linked hydrogels. The RF hydrogels may then be washed with an organic solvent to remove unreacted residuals. To obtain solid mesoporous RF gels, the RF hydrogels have to be carefully dried to remove water from their pore structures by a suitable drying method that could maintain the mesopores formed in the tenuous networks. The three typical drying techniques [12] are supercritical drying with carbon dioxide, freezing drying with solvent exchange, and conventional drying in an inert atmosphere (air/nitrogen), which yield solid-dried RF gels called RF aerogels, RF cryogels, and RF xerogels, respectively. The $\mathrm{CO}_{2}$-supercritical drying is the most suitable method for obtaining RF gels with excellent mesoporous property because the solvent is removed under supercritical conditions where the pores are free from capillary forces, thereby eliminating the shrinkage and collapse of pore structure. However, the cost of supercritical drying is extremely high. Though freeze-drying with solvent exchange is more economical compared with the supercritical and offers an effective alternative to prepare mesoporous $\mathrm{RF}$ gels with controlled pore structure, it is still expensive and time-consuming in terms of operating cost and solvent exchange step [13]. Though drying in inert atmosphere, especially hot-air drying, is the simplest and cheapest means, the resultant surface area, pore volume and average pore size of RF xerogels are significantly smaller than their aerogel and cryogel counterparts [12]. These inferior properties may be attributed to the partial collapse of their tenuous pore structures during water evaporation due to high capillary forces exerted by water surface tension. Alternatively, the production cost may be minimized if expensive and complicated drying processes (supercritical $\mathrm{CO}_{2}$ drying and freeze-drying) could be avoided by synthesis of high-quality RF-hydrogels with strong pore structures that can be maintained during conventional hot-air drying.

The primary objective of this work is to hydrothermally synthesize high-quality RF hydrogels that can undergo hot-air drying to yield good-quality mesoporous RF xerogels. More specifically, RF hydrogel synthesis was carried out in an autoclave which is a closed system at elevated pressure and temperature to strengthen the hydrogel structure while suppressing evaporation of water molecules under autogenous pressure. The hydrothermal temperature and initial $\mathrm{pH}$ of solution were varied in search of a suitable condition that minimizes structural collapse during subsequent hot-air drying.

\section{Materials and Methods}

\subsection{Chemicals}

RF hydrogels were synthesized by polycondensation of resorcinol (1, 3-dihydroxybenzene, $\mathrm{C}_{6} \mathrm{H}_{4}(\mathrm{OH})_{2}, 99 \%$ purity from E. Merck) with 36\% methanol-stabilized formaldehyde (HCHO, Fluka Chemie). Sodium 
carbonate $\left(\mathrm{Na}_{2} \mathrm{CO}_{3}\right.$, E. Merck) was used as basic catalyst, and distilled water as solvent. The sol-gel polycondensation took place in a $50 \mathrm{~mL}$-Teflon-lined stainless steel autoclave (see Fig. 1 (a)-(b)) containing multiple inserted glass tubes (illustrated in Fig. 2(b)) with inside diameter and length of $3.0 \mathrm{~mm}$ and 50.0 $\mathrm{mm}$, respectively.

\subsection{Synthesis and Characterization of Mesoporous RF Xerogels}

RF solution was prepared according to the method first proposed by Pekala [11]. First, resorcinol (R) was dissolved in distilled water $(\mathrm{W})$ at a predetermined R/W molar ratio of 0.041 . Next, formaldehyde $(\mathrm{F})$ with a fixed R/F molar ratio of 0.5 was mixed in the solution and a small designated amount of sodium carbonate catalyst (C) was gradually added dropwise while stirring for 30 min to obtain a homogeneous clear solution. Then the RF solution was filled in the glass tube molds and aged at elevated temperature to complete polycondensation reactions, thereby becoming solid RF hydrogel monoliths.

Two different sets of aging experiments, namely, conventional aging in open atmosphere at $160{ }^{\circ} \mathrm{C}$ and hydrothermal aging in the autoclave illustrated in Fig. 1 (a closed system with autogenous pressure) were carried out to compare their effect on the mesoporosity of resultant RF xerogels.
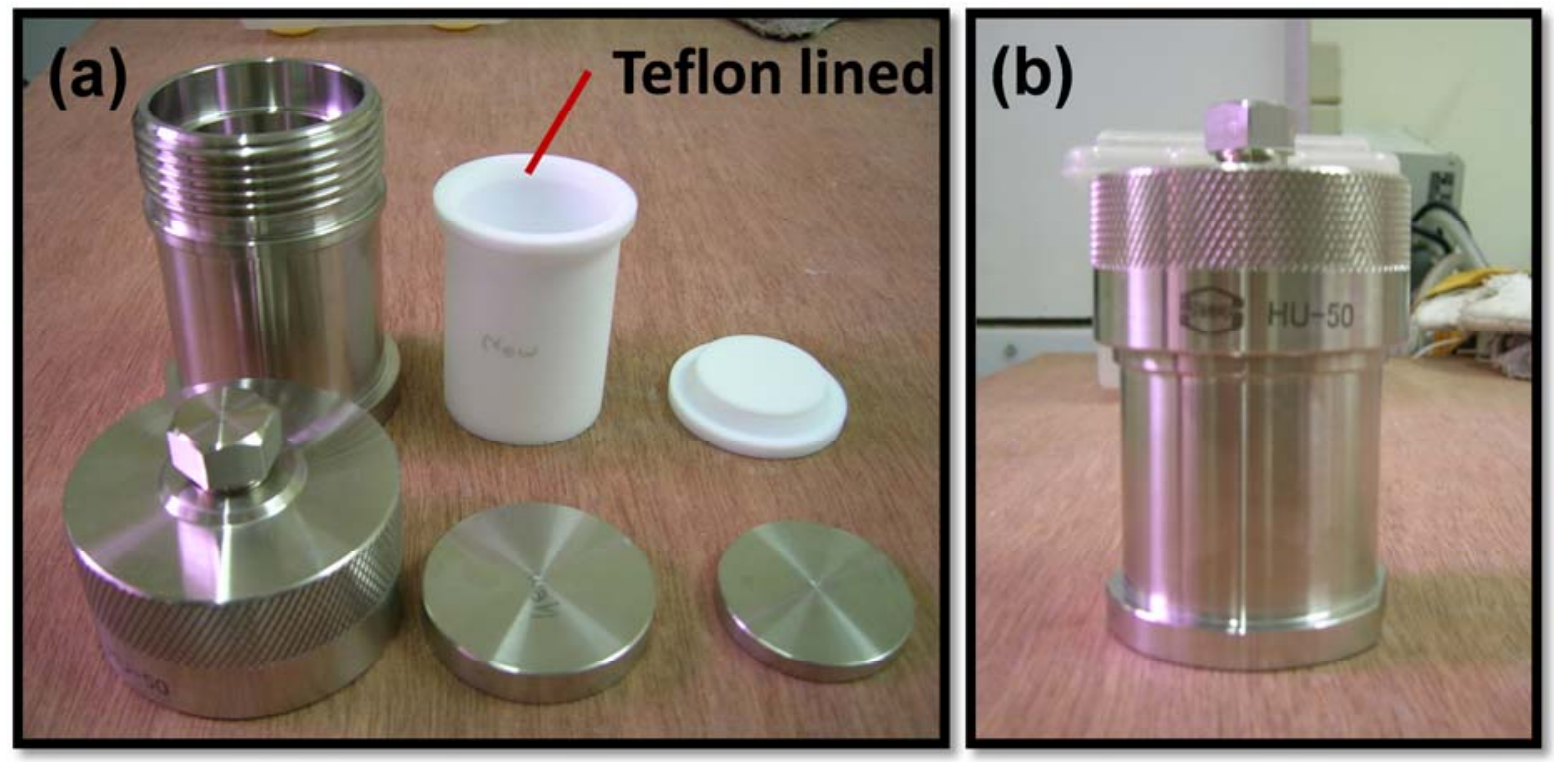

Fig.1. Illustrations of (a) the components of an autoclave, and (b) the assembled stainless steel autoclave.

In the first set of aging experiments, the initial $\mathrm{pH}$ of $\mathrm{RF}$ solutions was varied from 4.0 to 7.0 by changing the amount of added catalyst to investigate its effect on the porous structure of atmospheric RF xerogels. To age the RF solution, the filled glass tube molds were heated up in an oven to a reaction temperature of $160{ }^{\circ} \mathrm{C}$ in open atmosphere for 48 hours. In the second set of aging experiments, the filled glass tubes with a predetermined $\mathrm{pH}$ of 6.0 were put in the autoclave as shown in Fig. 2. Next, the autoclave was put in the oven, where a designated reaction temperature was provided. The aging step was held isothermally for 48 hours. Then the autoclave was left to cool naturally to room temperature. In either case, the monolithic RF hydrogel samples were taken out to undergo removal of water solvent by conventional hot-air drying at $40{ }^{\circ} \mathrm{C}$ for 72 hours and become RF xerogels. To investigate the effect of hydrothermal condition on the porous structure, the hydrothermal temperature was varied from 140 to 200 ${ }^{\circ} \mathrm{C}$ while the molar ratios between $\mathrm{R} / \mathrm{F}$ and $\mathrm{R} / \mathrm{W}$ as well as initial $\mathrm{pH}$ were fixed at $0.5,0.041$, and 6.0 , respectively [13]. The porous properties of RF xerogels were analyzed by a BET analyzer using adsorptiondesorption of nitrogen at $77 \mathrm{~K}$ (BEL: BELSORP-mini, Japan). The mesopore size was defined according to IUPAC $(2 \mathrm{~nm}<$ pore diameter $<50 \mathrm{~nm})$. Surface area, $V_{T}$, and $d_{\text {arg }}$ were calculated by BET method. Mesopore volume was determined according to BJH method. Micropore volume was determined according to t-plot method. 
(a)

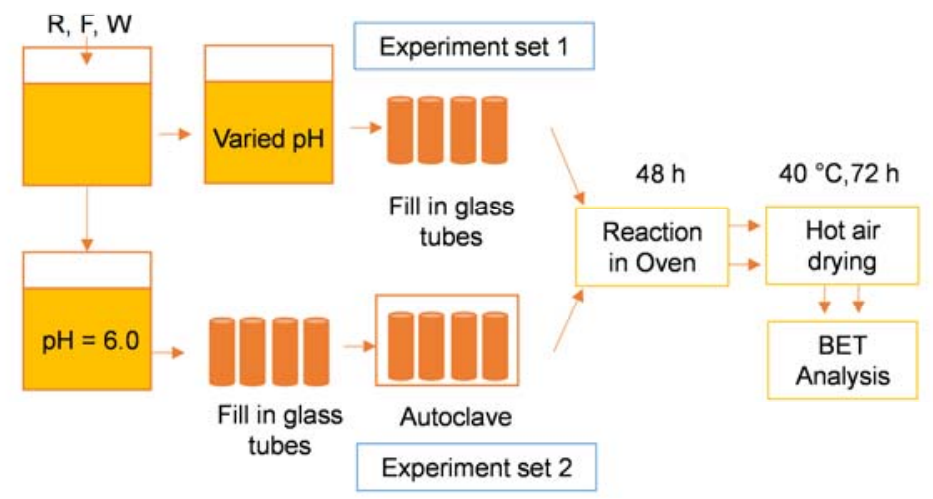

(b)

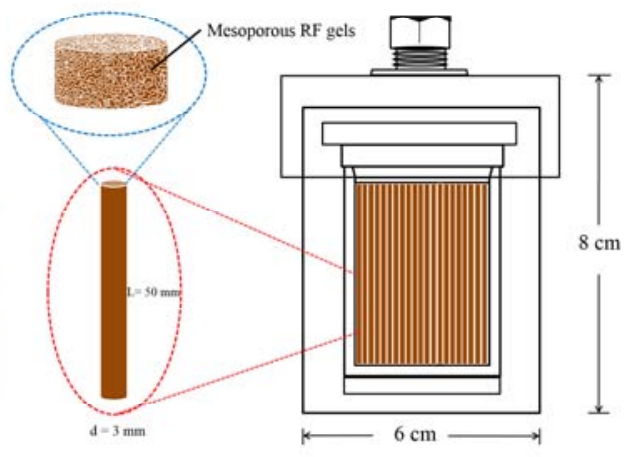

Fig. 2. Illustrations of (a) two different sets of aging experiments, and (b) RF gel monolith (left) and autoclave configuration (right).

\section{Results and Discussion}

\subsection{Atmospheric RF Xerogels: Effect of Initial pH Solution on Surface Area, Pore Volume and Pore Structure}

Table 1 summarizes the synthesis conditions of all RF xerogels synthesized via atmospheric and hydrothermal preparation, and their corresponding porous properties, including BET surface area $\left(S_{B E T}\right)$, total pore volume $\left(V_{T}\right)$, mesopore volume $\left(V_{\text {mess }}\right)$, micropore volume $\left(V_{\text {micro }}\right), r_{\text {peak }}$, and average pore size $\left(d_{a v g}\right)$. The $r_{\text {peak }}$ denotes the pore size at which a peak value or mode of the pore size distribution from BJH method is observed.

Table 1 Synthesis conditions and porous properties of air-dried RF xerogels.

\begin{tabular}{ccccccccccccc}
\hline Sample & $\mathrm{R} / \mathrm{F}$ & $\mathrm{R} / \mathrm{W}$ & $\mathrm{R} / \mathrm{C}$ & $\mathrm{pH}$ & $\begin{array}{c}\mathrm{T} \\
{\left[{ }^{\circ} \mathrm{C}\right]}\end{array}$ & System & $\begin{array}{c}S_{B E T} \\
{\left[\mathrm{~m}^{2} / \mathrm{g}\right]}\end{array}$ & $\begin{array}{c}V_{T} \\
{\left[\mathrm{~cm}^{3} / \mathrm{g}\right]}\end{array}$ & $\begin{array}{c}V_{\text {mes }} \\
{\left[\mathrm{cm}^{3} / \mathrm{g}\right]}\end{array}$ & $\begin{array}{c}V_{\text {micro }} \\
{\left[\mathrm{cm}^{3} / \mathrm{g}\right]}\end{array}$ & $\begin{array}{c}r_{\text {peak }} \\
{[\mathrm{nm}]}\end{array}$ & $\begin{array}{c}d_{\text {avg }} \\
{[\mathrm{nm}]}\end{array}$ \\
\hline pH-4 & 0.5 & 0.041 & 100 & 4 & 160 & atmospheric & 189 & 0.18 & $\mathrm{ND}$ & 0.18 & $\mathrm{ND}$ & 3.8 \\
pH-5 & 0.5 & 0.041 & 150 & 5 & 160 & atmospheric & 248 & 0.19 & $\mathrm{ND}$ & 0.19 & $\mathrm{ND}$ & 3.1 \\
pH-6 & 0.5 & 0.041 & 200 & 6 & 160 & atmospheric & 277 & 0.17 & $\mathrm{ND}$ & 0.17 & $\mathrm{ND}$ & 2.5 \\
pH-7 & 0.5 & 0.041 & 250 & 7 & 160 & atmospheric & 202 & 0.14 & $\mathrm{ND}$ & 0.14 & $\mathrm{ND}$ & 2.8 \\
$\mathrm{~T}-140$ & 0.5 & 0.041 & 200 & 6 & 140 & autoclave & 363 & 0.35 & 0.28 & 0.06 & 2.38 & 3.8 \\
T-160 & 0.5 & 0.041 & 200 & 6 & 160 & autoclave & 251 & 0.22 & 0.19 & 0.01 & 1.64 & 3.6 \\
T-180 & 0.5 & 0.041 & 200 & 6 & 180 & autoclave & 183 & 0.16 & 0.11 & 0.01 & 1.21 & 3.4 \\
T-200 & 0.5 & 0.041 & 200 & 6 & 200 & autoclave & 131 & 0.13 & 0.10 & 0.02 & 1.85 & 3.9 \\
\hline
\end{tabular}

Figure 3 illustrates that the adsorption/desorption isotherms of all four atmospheric RF xerogels prepared at different initial $\mathrm{pH}$ belonged to type I in IUPAC classification. This type I isotherm is typical microporous materials with exposed surfaces residing almost exclusively inside the microspores which, once filled with adsorbate, leave little external surface for further adsorption. This type I isotherm also indicates the absence of mesopores in the prepared-atmospheric RF xerogels. 


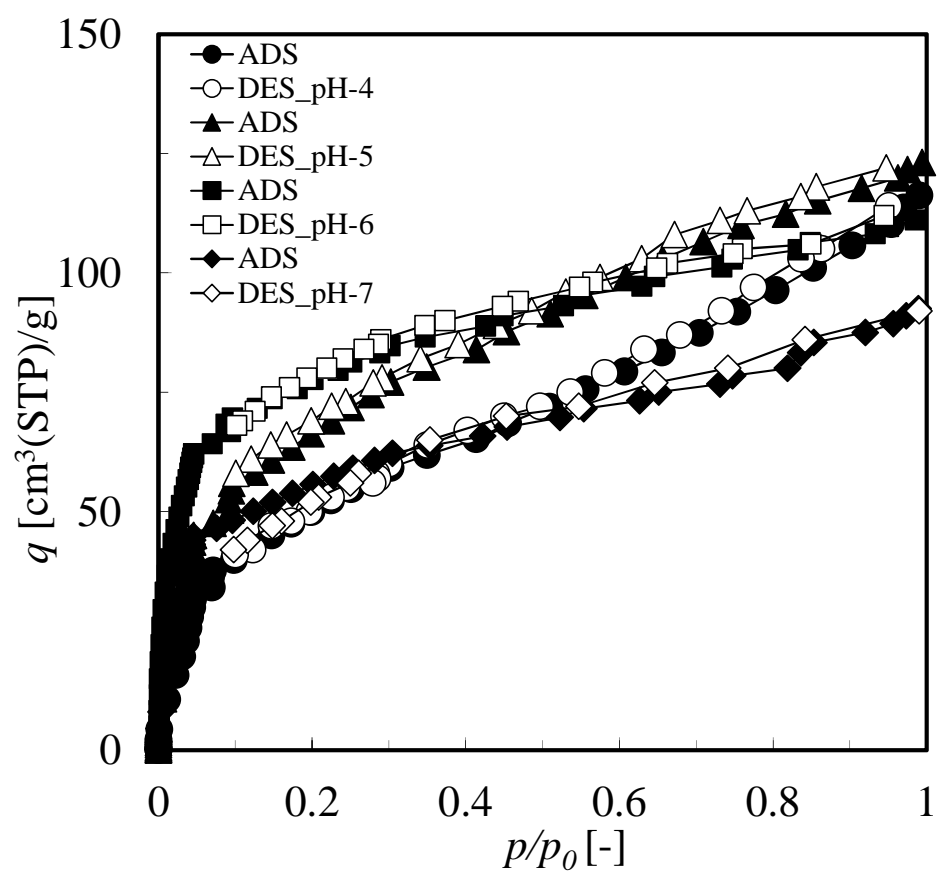

Fig. 3. Effect of initial $\mathrm{pH}$ of solution on $\mathrm{N}_{2}$ adsorption-desorption isotherms of atmospheric RF xerogels.

Similarly, Fig. 4 and Table 1 show the effect of the initial $\mathrm{pH}$ on the $S_{B E T}$, and $V_{T}$ of the atmospheric RF xerogels, whereas Fig. 5 shows the corresponding pore size distributions. Obviously, RF xerogels synthesized with an initial neutral $\mathrm{pH}$ of 7.0 possessed relatively low surface area of $202 \mathrm{~m}^{2} / \mathrm{g}$. Interestingly, as the $\mathrm{pH}$ decreased from 7.0 (neutral) to 6.0 (slightly acidic), the surface area increased remarkably from 202 to $277 \mathrm{~m}^{2} / \mathrm{g}$. This may be attributed to the simultaneous increase in pore volume (from 0.14 to 0.17 $\mathrm{cm}^{3} / \mathrm{g}$ ) and decrease in pore size (from 2.8 to $2.5 \mathrm{~nm}$ ). In addition, it is known that a lower initial $\mathrm{pH}$ (more acidic) would catalytically promote the structure-forming condensation reaction, thereby forming a relatively strong cross-linked structure where the majority of the pores would still remain intact during the drying step [15]. However, the surface area decreased monotonically over the $\mathrm{pH}$ range of 6.0 to 4.0 as shown in Fig. 4 and Table 1, mainly because a more acidic condition would promote formation of larger sol particles, bigger primary particles, thereby resulting in wider interparticle spaces and relatively larger micropores, which could contribute to less surface area. As a result, the average pore size increased significantly from 2.5 to $3.8 \mathrm{~nm}$ while the pore volume remained more or less the same. In fact, Table 1 and Fig. 5 clearly reveal that a lower $\mathrm{pH}$ (more acidic) would tend to produce not only a larger pore size but also a broader pore size distribution. This trend is consistent with the observed trends of pore volume shown in Fig. 4 and also reported for cryogels [16]. 


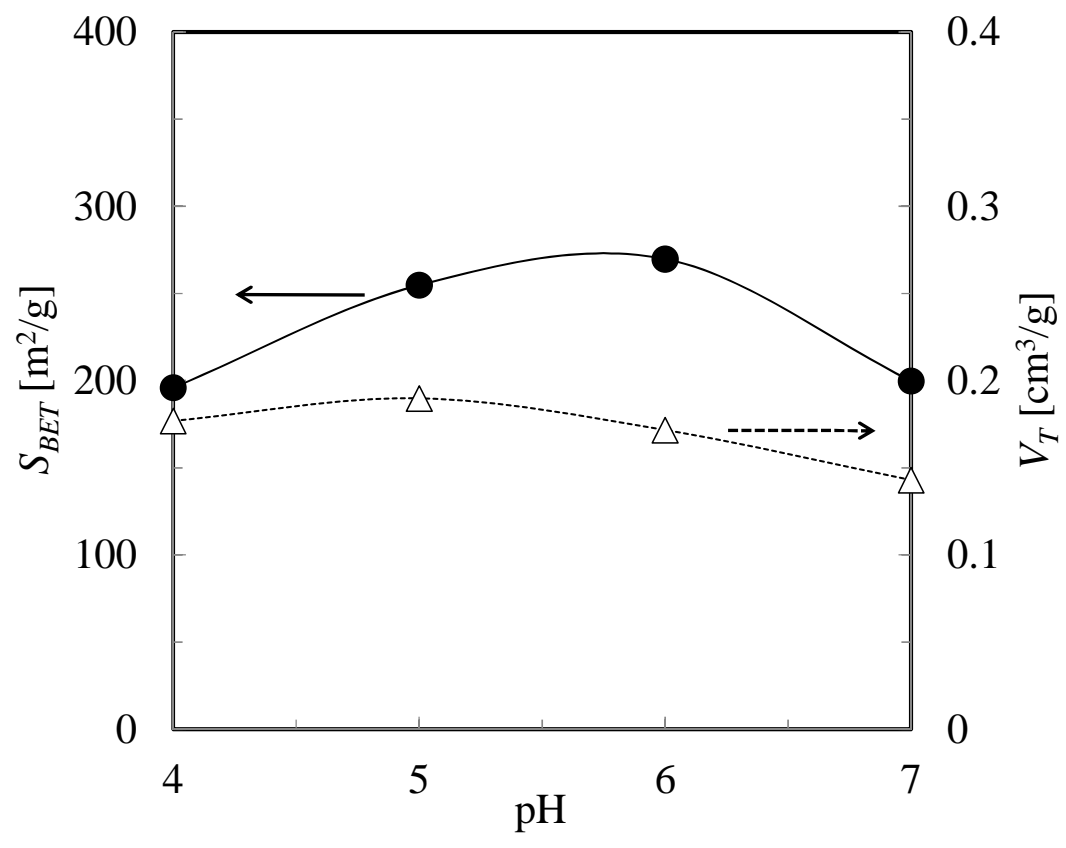

Fig. 4. Effect of initial pH of RF solution on surface area and pore volume of atmospheric RF xerogels.

Meanwhile, the sheer effect of reaction pressure on the porous property of xerogels could be observed by comparing samples prepared under atmospheric pressure with $p H$ of 6 to those at $T$ of $160{ }^{\circ} \mathrm{C}$ under autogenous steam saturation pressure of $0.63 \mathrm{MPa}$. The latter samples had significantly larger pore volume and pore size than the former because of 2 main reasons. First, the autoclave allowed autogenous pressure buildup that completely suppressed evaporation and escape of water molecules from the forming pores. Secondly, the stronger pre-stressed nanostructure of the latter samples resulted in less shrinkage and collapse, thereby maintaining larger pore volume and size. On the other hand, despite a smaller pore volume the former samples still managed to exhibit a slightly larger surface area due to significantly smaller pore size.

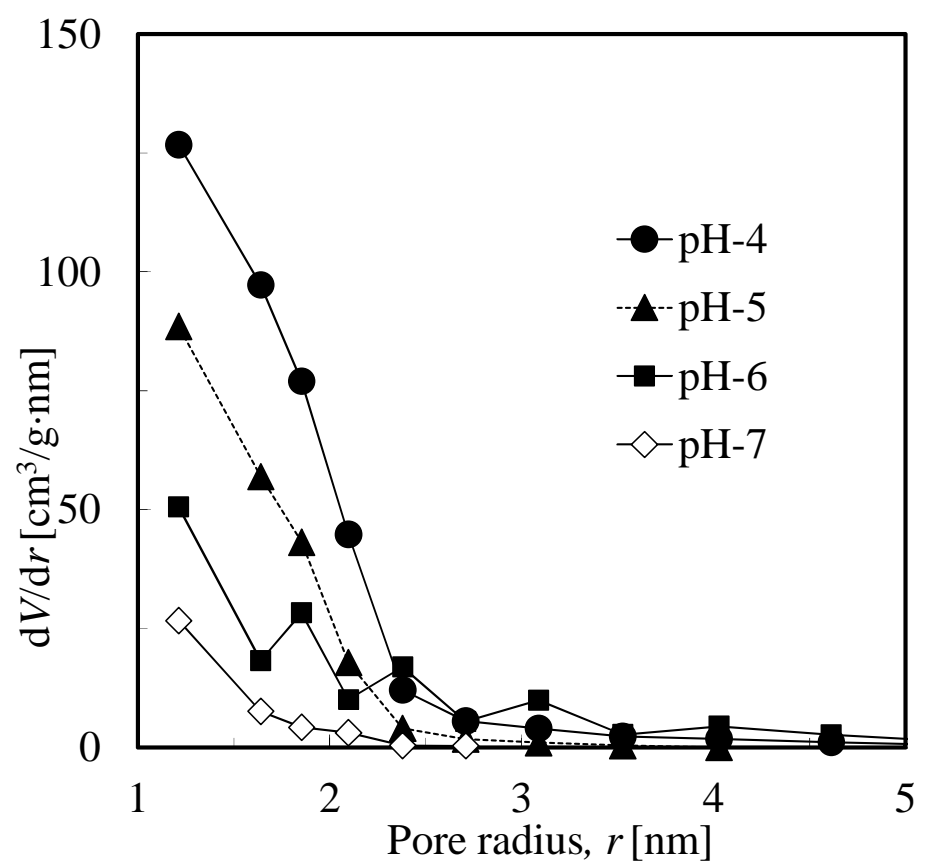

Fig. 5. Effect of initial $\mathrm{pH}$ of RF solution on pore size distributions of atmospheric RF xerogels. 


\subsection{Hydrothermal RF Xerogels: Effect of Hydrothermal Temperature on the Surface Area, Pore Volume and Pore Structure}

Since the RF solution with initial $\mathrm{pH}=6$ was found to clearly provide the highest surface area despite a slightly smaller pore volume as mentioned in section 3.1, this $\mathrm{pH}$ value was used in the second experimental set (hydrothermal process in autoclave). The investigated hydrothermal temperatures of 140, 160, 180, and $200{ }^{\circ} \mathrm{C}$ had corresponding steam saturation pressures of $0.36,0.63,1.00$ and $1.57 \mathrm{MPa}$, respectively. Fig. 6 and 7 show $\mathrm{N}_{2}$ adsorption-desorption isotherms of RF xerogels prepared at different hydrothermal temperature and the corresponding surface area and total pore volume, respectively. Meanwhile, Fig. 8 shows the effect of hydrothermal temperature on pore size distribution. As shown in Fig. 6, all isotherms were similar and exhibited a type IV $\mathrm{N}_{2}$ isotherm with a type $\mathrm{H} 2$ hysteresis loop [17]. This combination of the 2 features was usually attributed to capillary condensation of $\mathrm{N}_{2}$ occurring in the mesopores and was similar to those observed for sol-gel derived inorganic oxide xerogels. It should be noted that type II hysteresis loop was very complex, and might result from not only "ink bottle" shaped pores but also crosslinked networking [17]. In any case, Fig. 6 and 8 confirm that the hydrothermal RF xerogels exhibit significant mesoporosity.

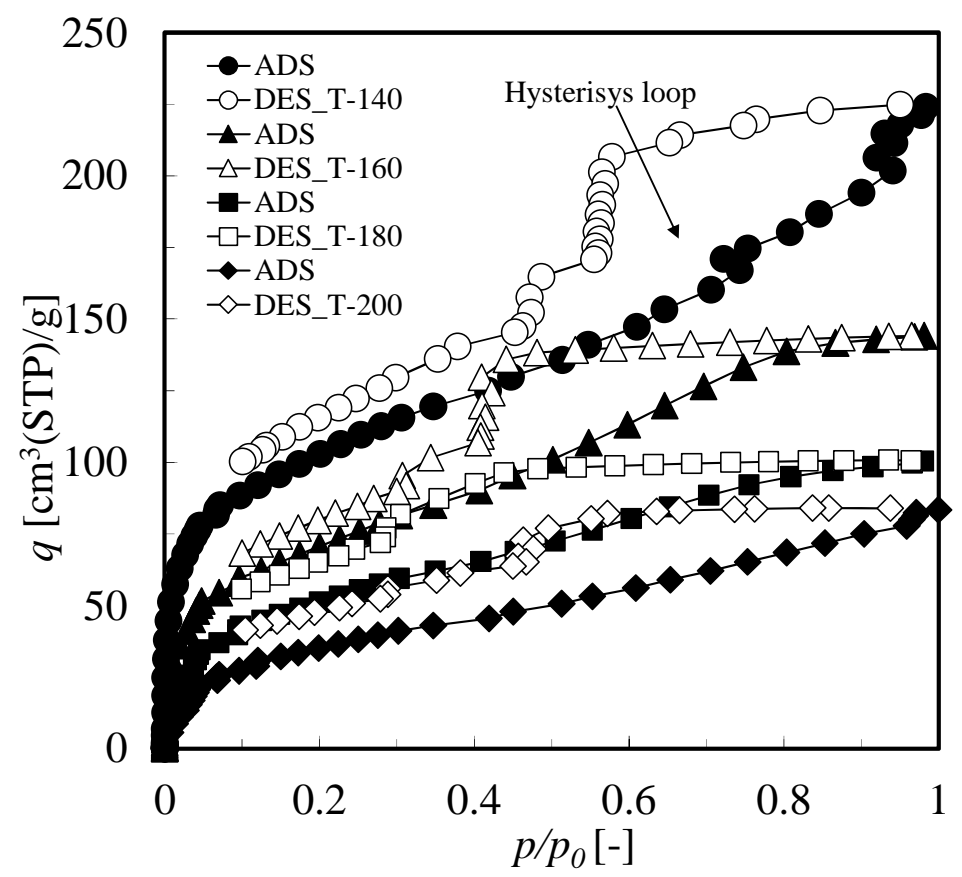

Fig. 6. Effect of hydrothermal temperature on $\mathrm{N}_{2}$ adsorption-desorption isotherms of hydrothermal $\mathrm{RF}$ xerogels.

Figure 7 and Table 1 reveal that, as the hydrothermal temperature decreased from 200 to $140{ }^{\circ} \mathrm{C}$, both the surface area and pore volume increased remarkably from 131 to $363 \mathrm{~m}^{2} / \mathrm{g}$, and from 0.13 to $0.35 \mathrm{~cm}^{3} / \mathrm{g}$, respectively, while the average pore sizes remain nearly the same. Similar to the catalytic effect of a more acidic $\mathrm{pH}$, a higher temperature would accelerate reactions and result in a fewer number of larger primary particles. This then led to the formation of a three-dimensional network structure with thicker walls and a smaller size of xerogel with higher density and less pore volume. Since there was negligible shrinkage of all hydrothermal gel samples during drying, their gel network as well as total pore volume and average pore size would remain unchanged $[13,18,19,20]$. Because of the unchanged pore size, the increase in pore volume would contribute proportionally to the increase in surface area. 


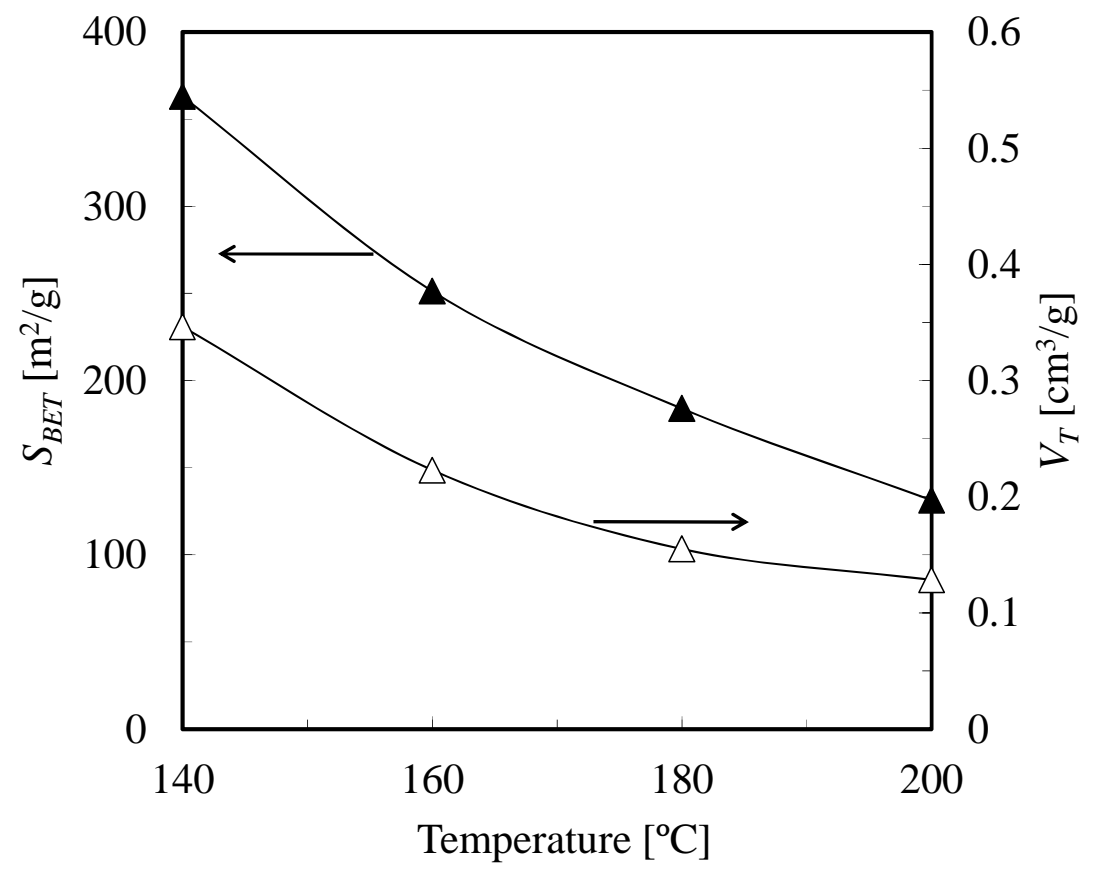

Fig. 7. Effect of hydrothermal temperature on the surface area and pore volume of hydrothermal RF xerogels.

Figure 8 and Table 1 reveal that the values of $r_{\text {peak }}$ and $V_{\text {mes }}$ of RF xerogels increased as the hydrothermal temperature decreased. More specifically, the lowest hydrothermal temperature of $140{ }^{\circ} \mathrm{C}$ (Sample T-140) resulted in a bimodal pore size distribution of larger pore size with $r_{\text {peak }}=2.38 \mathrm{~nm}$. In contrast, the pore size distribution of Sample $T-160$ was unimodal with smaller pore size and $r_{\text {peak }}=1.64 \mathrm{~nm}$. The T-140 xerogel sample was composed of more than $80 \%$ mesoporosity compared to its total pore volume. This result was consistent with its isotherm with a large hysteresis loop as shown in Fig. 6.

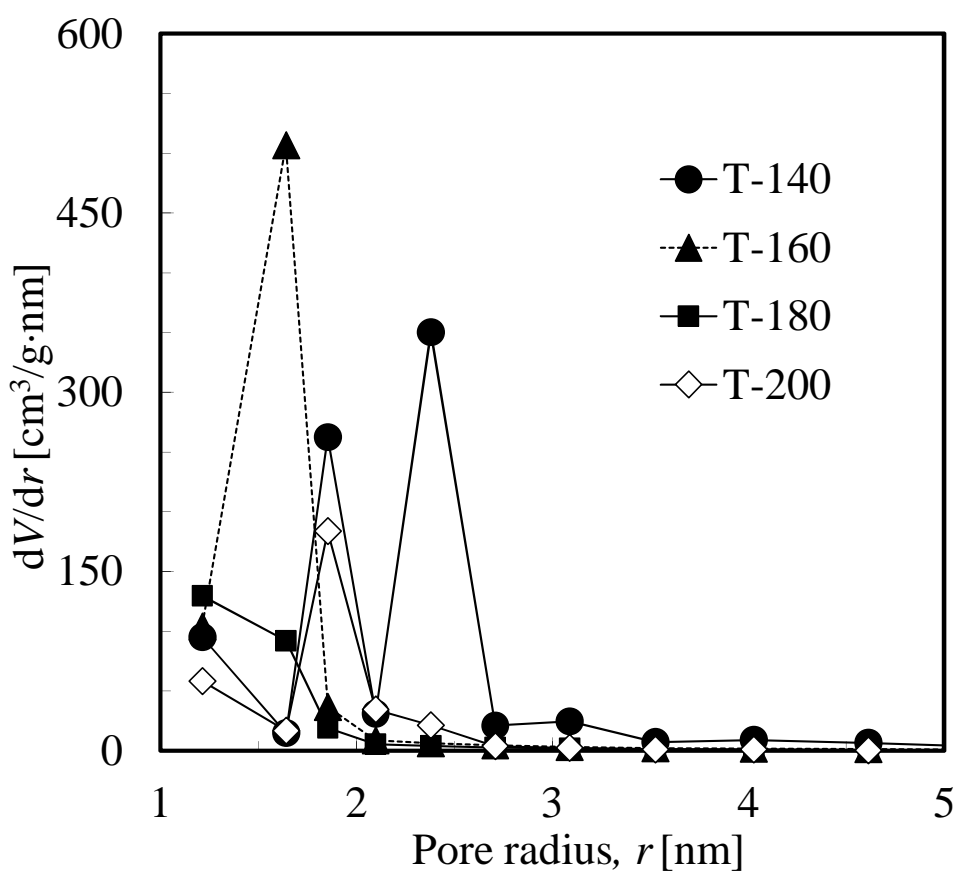

Fig. 8. Pore size distributions of hydrothermal RF xerogels synthesized at various hydrothermal temperatures. 
It should be noted that, in the case of conventional atmospheric sol-gel synthesis, RF gelation and aging are normally carried out below the boiling point of the RF solution (below boiling point of water solvent, $\left.100{ }^{\circ} \mathrm{C}\right)$. More specifically, the hydrogels are usually aged at low temperature $\left(25-90^{\circ} \mathrm{C}\right)$ for many days to form cross-linked network which could sufficiently strengthen its structure before hot-air drying. To elucidate the advantage of the present hydrothermal process over the conventional process, our T-140 xerogels were compared with those reported for conventionally synthesized samples in the literature. Tamon et al. [13] reported that the RF sols were gelled by aging them at atmospheric pressure, first at $25^{\circ} \mathrm{C}$ for 1 day, at $50{ }^{\circ} \mathrm{C}$ for 1 day and then at $90{ }^{\circ} \mathrm{C}$ for 3 days to obtain $\mathrm{RF}$ hydrogels which were subsequently dried in an oven kept at $50{ }^{\circ} \mathrm{C}$ for 48 hours to yield RF xerogels. The R/F ratio and $\mathrm{R} / \mathrm{C}$ ratio of their solutions were the same as those of our T-140 whereas their $\mathrm{R} / \mathrm{W}$ ratios were 0.0204 and 0.0613 . The corresponding surface area, pore volume and pore size for their both samples were $152 \mathrm{~m} / \mathrm{g}, 0.27 \mathrm{~m}^{3} / \mathrm{g}$, $3.6 \mathrm{~nm}$ and $255 \mathrm{~m}^{2} / \mathrm{g}, 0.31 \mathrm{~m}^{3} / \mathrm{g}, 3.6 \mathrm{~nm}$, respectively. Since the effect of the R/W ratio on both surface area and pore volume may be assumed to be linear [13], the corresponding characteristics of their RF xerogel aged at atmospheric pressure with $\mathrm{R} / \mathrm{W}$ ratio of 0.041 would be estimated to be about $204 \mathrm{~m}^{2} / \mathrm{g}$, $0.29 \mathrm{~m}^{3} / \mathrm{g}$ and $3.6 \mathrm{~nm}$, respectively. Meanwhile, the corresponding values of T-140 with the same R/W ratio of 0.041 were $363 \mathrm{~m}^{2} / \mathrm{g}, 0.35 \mathrm{~m}^{3} / \mathrm{g}$ and $3.8 \mathrm{~nm}$. Therefore, with respect to our hydrothermal samples, the surface area and pore volume significantly increased by almost $80 \%$ and $20 \%$, respectively, whereas the pore size slightly increased from 3.6 to $3.8 \mathrm{~nm}$. This superior porous property of $T-140$ xerogels may be ascribed to effective strengthening of RF hydrogel structure during hydrothermal process at elevated temperature and pressure.

Figure 9 shows SEM images of the cross sections of RF xerogel sample T-140. Fig. 9(a) provides evidence that its macroscopic structure was composed of interconnected secondary particles. The macropores were in effect the "macrovoids" formed between the secondary particles. The macrovoid size ranged from 200 to $800 \mathrm{~nm}$. The obtained T-140 RF xerogels had a hierarchical pore system of micro-, meso- and macro-pores with high specific surface area and large pore volume. It is known that such a hierarchical pore system enables more efficient mass transport into and out of the porous material than a unimodal pore system with the same total surface area. In addition, mesoporous RF xerogels could be further carbonized to obtain thermally stable mesoporous RF carbon gels with slightly more micropores and higher surface area which could be useful for many potential applications.

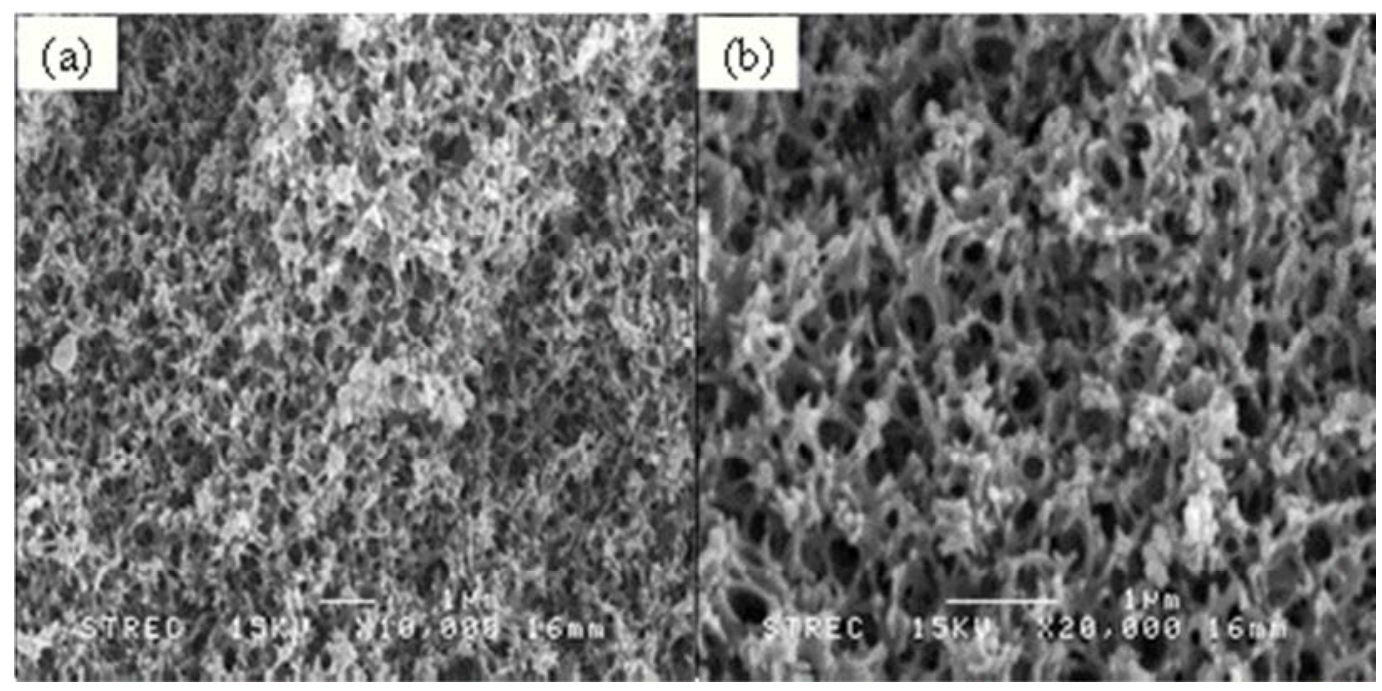

Fig. 9. SEM images of hydrothermal RF xerogel (T-140) at (a) low magnification and (b) high magnification of 10000 and 20000 , respectively.

\section{Conclusions}

Hot-air dried mesoporous RF xerogels with a hierarchical pore system of micro-, meso-, and macro-pore were successfully synthesized by sol-gel polycondensation of resorcinol with formaldehyde using a facile hydrothermal process in the autoclave. The process was on the overall relatively simple, low-cost, and less time-consuming when compared to the conventional atmospheric method which required long aging time 
and/or sophisticated drying methods. The optimum hydrothermal temperature and initial $\mathrm{pH}$ of $\mathrm{RF}$ solution were found to be $140{ }^{\circ} \mathrm{C}$ and 6 , respectively. The result of this work could provide a novel practical method for producing RF gels with remarkably high mesoporosity, large surface area and large pore volume. In addition, usage of a closed autoclave system also prevents emission of hazardous formaldehyde to the environment during the aging step.

\section{Acknowledgement}

This work was partially supported by a grant of Chulalongkorn University via Centenary Academic Development Project to the Center of Excellence in Particle Technology.

\section{References}

[1] S. A. Al-Muhtaseb, and J. A. Ritter, "Preparation and properties of resorcinol-formaldehyde organic and carbon gels," Adv. Mater., vol. 15, pp. 101-114, 2003.

[2] H. Tamon, H. Ishizaka, M. Mikami, and M. Okazaki, "Porous structure of organic and carbon aerogels synthesized by sol-gel polycondensation of resorcinol with formaldehyde," Carbon, vol. 35, pp. 791-796, 1997

[3] C. Lin, and J. A. Ritter, "Carbonization and activation of sol-gel derived carbon xerogels," Carbon, vol. 38, pp. 849-861, 2000.

[4] T. Yamamoto, T. Sugimoto, T. Suzuki, S. R. Mukai, and H. Tamon, "Preparation and characterization of carbon cryogel microspheres," Carbon, vol. 40, pp. 1345-1351, 2002.

[5] K. Holmström, S. Gräslund, A. Wahlström, S. Poungshompoo, B. E. Bengtsson, and N. Kautsky, "Antibiotic use in shrimp farming and implications for environmental impacts and human health," Int. J. Food Sci. Technol., vol. 38, pp. 255-266, 2003.

[6] B. Liu, and S. Creager, "Carbon xerogels as Pt catalyst supports for polymer electrolyte membrane fuel-cell applications," J. Power Sources, vol. 195, pp. 1812-1820, 2010.

[7] T. Zheng, Y. Liu, E. W. Fuller, S. Tseng, U. von Sacken, and J.R. Dahn, "Lithium insertion in high capacity carbonaceous materials," J. Electrochem. Soc., vol. 142, pp. 2581-2590, 1995.

[8] R. W. Pekala, and F. M. Kong, "Resorcinol-formaldehyde aerogels and their carbonized derivatives," ACS. Polym. Prpts., Dallas, TX, USA: Publ by ACS., 1989.

[9] J. Ren, L. Jia, L. Xu, X. Lin, Z. Pi, and J. Xie, "Removal of autoantibodies by 4-mercaptoethylpyridinebased adsorbent," J. Chromatogr., B: Anal. Technol. Biomed. Life Sci., vol. 877, pp. 1200-1204, 2009.

[10] Y. Ein-Eli, B. Markovsky, D. Aurbach, Y. Carmeli, H. Yamin, and S. Luski, "The dependence of the performance of Li-C intercalation anodes for Li-ion secondary batteries on the electrolyte solution composition," Electrochim Acta., vol. 39, pp. 2559-2569, 1994.

[11] R. W. Pekala, "Organic aerogels from the polycondensation of resorcinol with formaldehyde," J. Mater. Sci., vol. 24, pp. 3221-3227, 1989.

[12] O. Czakkel, K. Marthi, E. Geissler, and K. László, "Influence of drying on the morphology of resorcinol-formaldehyde-based carbon gels," Microporous Mesoporous Mater., vol. 86, pp. 124-133, 2005.

[13] H. Tamon, H. Ishizaka, T. Yamamoto, and T. Suzuki, "Influence of freeze-drying conditions on the mesoporosity of organic gels as carbon precursors," Carbon, vol. 38, pp. 1099-1105, 2000.

[14] B. Babić, B. Kaluđerović, L. Vračar, and N. Krstajić, "Characterization of carbon cryogel synthesized by sol-gel polycondensation and freeze-drying," Carbon, vol. 42, pp. 2617-2624, 2004.

[15] N. Job, R. Pirard, J. Marien, and J. P. Pirard, "Porous carbon xerogels with texture tailored by $\mathrm{pH}$ control during sol-gel process," Carbon, vol. 42, pp. 619-628, 2004.

[16] H. Tamon, H. Ishizaka, T. Yamamoto, and T. Suzuki, "Preparation of mesoporous carbon by freeze drying," Carbon, vol. 37, pp. 2049-2055, 1999.

[17] S. J. Gregg, and K. S. W. Sing, Adsorption, Surface Area, and Porosity, 2nd ed., Academic, London, 1982

[18] C. Lin, and J. A. Ritter, "Effect of synthesis $\mathrm{pH}$ on the structure of carbon xerogels," Carbon, vol. 35, pp. 1271-1278, 1997.

[19] H. Tamon, and H. Ishizaka, "Preparation of organic mesoporous gel by supercritical/freeze drying," Drying Technol., vol. 17, pp. 1653-1665, 1999.

[20] H. Tamon, H. Ishizaka, T. Araki, and M. Okazaki, "Control of mesoporous structure of organic and carbon aerogels," Carbon, vol. 36, pp. 1257-1262, 1998. 